\title{
Prevention of type 2 diabetes mellitus in women with previous gestational diabetes mellitus
}

\author{
Joon Ho Moon ${ }^{1,2,}$, Soo Heon Kwak ${ }^{1,2}$, and Hak C. Jang ${ }^{1,3}$
}

\begin{abstract}
${ }^{1}$ Department of Internal Medicine, Seoul National University College of Medicine, Seoul; ${ }^{2}$ Department of Internal Medicine, Seoul National University Hospital, Seoul; ${ }^{3}$ Department of Internal Medicine, Seoul National University Bundang Hospital, Seongnam, Korea
\end{abstract}

\author{
Received: May 28, 2016 \\ Accepted: December 12, 2016 \\ Correspondence to \\ Hak C. Jang, M.D. \\ Department of Internal \\ Medicine, Seoul National \\ University Bundang Hospital, \\ 82 Gumi-ro 173beon-gil, Bun- \\ dang-gu, Seongnam 13620, Korea \\ Tel: +82-31-787-7005 \\ Fax: $+82-31-787-4051$ \\ E-mail:janghak@snu.ac.kr \\ *Current affiliation: Graduate \\ School of Medical Science and \\ Engineering, Korea Advanced \\ Institute of Science and Technol- \\ ogy, Daejeon, Korea
}

Gestational diabetes mellitus (GDM), defined as any degree of glucose intolerance with onset or first recognition during pregnancy, is characterized by underlying maternal defects in the $\beta$-cell response to insulin during pregnancy. Women with a previous history of GDM have a greater than 7-fold higher risk of developing postpartum diabetes compared with women without GDM. Various risk factors for postpartum diabetes have been identified, including maternal age, glucose levels in pregnancy, family history of diabetes, pre-pregnancy and postpartum body mass index, dietary patterns, physical activity, and breastfeeding. Genetic studies revealed that GDM shares common genetic variants with type 2 diabetes. A number of lifestyle interventional trials that aimed to ameliorate modifiable risk factors, including diet, exercise, and breastfeeding, succeeded in reducing the incidence of postpartum diabetes, weight retention, and other obesity-related morbidities. The present review summarizes the findings of previous studies on the incidence and risk factors of postpartum diabetes and discusses recent lifestyle interventional trials that attempted to prevent postpartum diabetes.

Keywords: Diabetes, gestational; Diabetes mellitus, type 2; Epidemiology; Risk factors; Clinical trial

\section{INTRODUCTION}

Gestational diabetes mellitus (GDM) is defined as any degree of glucose intolerance with onset or first recognition during pregnancy [1]. In parallel to the current obesity epidemic, the prevalence of GDM has continuously increased globally [2]. In Korea, the prevalence of GDM has increased in past decades and reached 10.5\% in 2011 [3]. Older maternal age and widespread screening for GDM have contributed to the increased prevalence of GDM in Korea [4].
GDM has its clinical implications for both perinatal and postpartum maternal outcomes [5]. Perinatal outcomes include preeclampsia, Cesarean section, macrosomia, neonatal hypoglycemia, and hyperbilirubinemia, of which the risk is increased in women with GDM. In addition, GDM has implications for postpartum metabolic conditions, as it is characterized by underlying defects in $\beta$-cell response due to increased insulin resistance during pregnancy. A prospective cohort study showed that women with previous GDM had a faster deterioration of $\beta$-cell secretory capacity and insulin 
sensitivity compared with their counterparts without GDM after delivery [6]. Therefore, women with a history of GDM are at elevated risk of postpartum diabetes and complications and may develop diabetes at an earlier age than women without GDM $[7,8]$. Metabolic impairments including dyslipidemia and vascular dysfunction are other possible complications in women with previous GDM $[9,10]$. This review will focus on the incidence of and risk factors for postpartum diabetes in women with a history of GDM and discuss recent interventional trials that aimed to improve postpartum metabolic phenotypes.

\section{DIAGNOSIS OF GDM AND POSTPARTUM DIA- BETES}

\section{Gestational diabetes mellitus}

The diagnostic criteria of GDM has its better clinical implication when it properly classify women at risk of poor pregnancy outcomes. The traditional 'two-step approach' (an 1-hour $50 \mathrm{~g}$ glucose challenge test for screening and a 3 -hour $100 \mathrm{~g}$ oral glucose tolerance test [OGTT] for confirmation) has been widely used to evaluate maternal hyperglycemia at 24 to 28 weeks of pregnancy $[1,11]$. Two representative criteria are available as confirmatory tests. The National Diabetes Data Group (NDDG) recommends criteria based on the results of O'Sullivan and Mahan [12], which require two or more of the following: fasting plasma glucose $\geq 105 \mathrm{mg} / \mathrm{dL}$, 1-hour levels $\geq 190 \mathrm{mg} / \mathrm{dL}, 2$-hour levels $\geq 165 \mathrm{mg} / \mathrm{dL}$, and 3-hour levels $\geq 145 \mathrm{mg} / \mathrm{dL}$. Nearly $50 \%$ of the women who were diagnosed with GDM using these criteria developed postpartum glucose intolerance in follow-up studies [13]. Later, Carpenter and Coustan [11] suggested more inclusive criteria for the GDM confirmatory test; they suggested that two or more of the following be present for a diagnosis of GDM: fasting plasma glucose $\geq 95 \mathrm{mg} / \mathrm{dL}$, 1-hour levels $\geq 180 \mathrm{mg} / \mathrm{dL}$, 2-hour levels $\geq$ $155 \mathrm{mg} / \mathrm{dL}$, and 3-hour levels $\geq 140 \mathrm{mg} / \mathrm{dL}$. Using these criteria, an additional $50 \%$ of women tested were diagnosed with GDM compared with those diagnosed using the NDDG criteria $[14,15]$. These criteria were recommended by the Fifth International Workshop Conference on Gestational Diabetes Mellitus [16].

The 'one-step strategy' for GDM diagnosis was sug- gested by the International Association of the Diabetes and Pregnancy Study Groups (IADPSG) in 2010 [17]. Using this strategy, women meeting one or more of the following criteria after a 2-hour $75 \mathrm{~g}$ OGTT are diagnosed with GDM: fasting plasma glucose $\geq 92 \mathrm{mg} / \mathrm{dL}$, 1-hour levels $\geq 180 \mathrm{mg} / \mathrm{dL}$, and 2-hour levels $\geq 153 \mathrm{mg} /$ dL. These cutoff values, derived from the Hyperglycemia and Adverse Pregnancy Outcome (HAPO) study, predict adverse pregnancy outcomes with an odds ratio of 1.75 [18]. Challenges associated with using the IADPSG criteria for GDM diagnosis include a high prevalence of GDM ( $17.8 \%$ of all pregnancies in the HAPO study) and poor reproducibility [19]. Currently, both the Korean Diabetes Association and the American Diabetes Association (ADA) recommend both the one- and two-step approaches for the diagnosis of GDM $[20,21]$.

\section{Postpartum screening of glucose tolerance status}

Women with a previous GDM diagnosis are encouraged to be screened for postpartum glucose intolerance. The ADA and the American College of Obstetricians and Gynecologists recommend that women with previous GDM undergo an OGTT at 6 to 12 weeks postpartum and to have lifelong evaluations for diabetes at least every 3 years $[20,22]$. Measurement of fasting plasma glucose is insufficient as a screening tool, as only $34 \%$ of women with diabetes or impaired glucose tolerance had impaired fasting glucose in a previous study [16]. Earlier studies [23,24] applied the following World Health Organization (WHO, year 1985) criteria [25] for the diagnosis of postpartum diabetes: fasting plasma glucose $\geq 140 \mathrm{mg} / \mathrm{dL}$ or 2 -hour levels $\geq 200 \mathrm{mg} / \mathrm{dL}$. In contrast, recent studies [26-28] have used the following diagnostic criteria from the ADA or WHO (year 1999) [20,29]: fasting plasma glucose $\geq 126 \mathrm{mg} / \mathrm{dL}$ or 2 -hour levels $\geq 200$ $\mathrm{mg} / \mathrm{dL}$. This resulted in diagnosing more individuals with postpartum diabetes compared with the previous WHO (year 1985) criteria [30]. Since 2010, the ADA has used a glycosylated hemoglobin ( $\mathrm{HbArc}$ ) value $\geq 6.5 \%$ for the diagnosis of diabetes; although this is widely used in clinical practice, it has yet to be applied to postpartum diabetes studies. Recent epidemiologic studies have reported that the increase in the prevalence of GDM and/ or type 2 diabetes is associated with the obesity epidemic [2,31], but changes in diagnostic criteria should be kept in mind when interpreting prevalence data. 


\section{POSTPARTUM DIABETES IN WOMEN WITH PREVIOUS GDM}

\section{Incidence of postpartum diabetes}

Previous epidemiologic studies on postpartum diabetes were conducted primarily in North America and Europe. Metzger et al. [32] recruited multi-ethnic women with GDM in Chicago and reported a 5-year cumulative incidence of postpartum diabetes of nearly $50 \%$. The incidence of postpartum diabetes increased more rapidly in the first 2 years postpartum. Retnakaran et al. [33] performed a prospective cohort study in Canada with a cohort consisting primarily of Caucasian individuals; this study found that $32.8 \%$ of women with GDM had either impaired glucose tolerance or diabetes at 3 months postpartum. A retrospective cohort study from Sweden reported a diabetes incidence of $35 \%$ among women with previous GDM during a 15-year follow-up period [34]. A systematic review by Kim et al. [7] found that the prevalence of postpartum diabetes ranged from $2.6 \%$ to $70 \%$, with rates differing according to study design, diagnostic methods, and ethnicity. Bellamy et al. [35] reviewed published cohort studies and demonstrated a 7.43-fold higher risk of postpartum diabetes in women with GDM compared with women who were normoglycemic during pregnancy.

A prospective cohort study in Korea reported a cu-

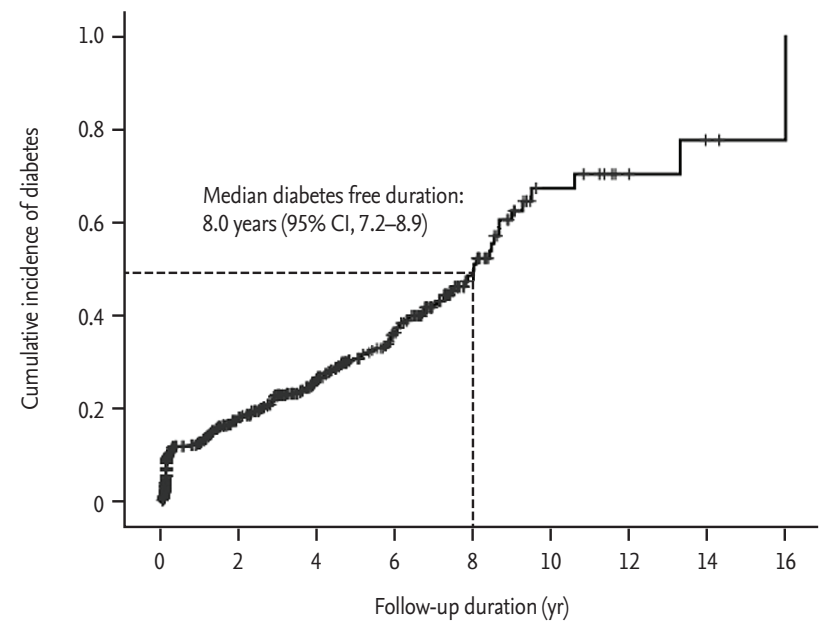

Figure 1. Cumulative incidence of type 2 diabetes after gestational diabetes mellitus pregnancy. CI, confidence interval. Adapted from Kwak et al. [36], with permission from Endocrine Society. mulative incidence of postpartum diabetes of $23.8 \%$ for a median duration of 4 years, and it expected an incidence of $50.0 \%$ during an 8-year follow-up period among women with previous GDM (Fig. 1) [36]. Another prospective cohort study by Cho et al. [37] reported an incidence of $12.8 \%$ and $13.2 \%$ of postpartum diabetes and impaired glucose tolerance, respectively, during a 6-year follow-up period (mean, $2.1 \pm 1.8$ years). The risk of postpartum diabetes in Korean women with GDM was 3.5-fold greater than that in women without GDM [38]. The incidence of postpartum diabetes in Korean women with GDM seems to be similar to that found in other studies conducted abroad.

\section{Factors affecting the incidence of postpartum diabetes}

\section{Ethnicity}

East Asians have a relatively low body mass index (BMI), and the underlying pathophysiology of diabetes in this population is thought to differ from that in other ethnicities [39]. In previous studies, the development of diabetes in Korean individuals was attributed to a genetic predisposition to $\beta$-cell dysfunction and/or impaired $\beta$-cell compensation to insulin resistance $[40,41]$.

(1) GDM: Hedderson et al. [42] compared ethnic differences in the prevalence of GDM based on BMI. Asian women had a higher prevalence of GDM compared with Caucasian women in the same BMI categories. This finding suggests that Asian women may have impaired $\beta$-cell compensation compared with women of other ethnicities with a similar extent of insulin resistance (or obesity). This suggest that the BMI goals for Asian women during pregnancy should be lower than those of Caucasian women. For instance, among Asian women at 17 weeks of gestation, BMIs less than $19 \mathrm{~kg} / \mathrm{m}^{2}$ (compared with those 19.0 to $21.9 \mathrm{~kg} / \mathrm{m}^{2}$ ) exerted protective effects on the development of GDM, whereas Caucasian women with BMIs less than $19 \mathrm{~kg} / \mathrm{m}^{2}$ did not show protective effects.

(2) Postpartum diabetes: Kousta et al. [43] recruited 368 women of European, Asian, and African ethnicities with previous GDM and demonstrated increased prevalences of impaired glucose tolerance ( $44 \%$ vs. $28 \%$ ) and metabolic syndrome (49\% vs. $28 \%$ ) among Asian women compared with European women at 20 months postpartum. Ignell et al. [44] compared postpartum glucose homeo- 
stasis between Asians and Europeans. Women of Asian ethnicity had a 5-fold higher risk of developing diabetes 1 to 2 years postpartum and showed a $22 \%$ decrease in their $\beta$-cell compensation measured using the disposition index. Further multi-ethnic studies are warranted to investigate the hypothesized increased susceptibility of postpartum diabetes among Asian populations.

\section{Duration after delivery}

It is known that the incidence of postpartum diabetes varies widely according to the duration of follow-up [7,35], but changes in incidence over time have not been well studied. In a systematic review, Kim et al. [7] argued that the incidence of postpartum diabetes increased steeply within the first 5 years postpartum and reached a plateau after 10 years. However, this should be carefully interpreted, as individual studies did not distinguish the incidence of early postpartum diabetes $(\leq 8$ weeks after delivery) from that of late conversion to diabetes but only determined the average incidence after several years of follow-up in each study. Studies from Korea reported that the incidence of early postpartum diabetes ( 6 to 8 weeks) was higher than 10\% [36,45]. This incidence rate (incidence per unit time) during the early postpartum period was much higher than the rate of $\sim 50 \%$ of postpartum diabetes in following 5 to 10 years [7]. Early converters to diabetes had greater impairment in their $\beta$-cell function during pregnancy than did late converters [36]. Studies with a longitudinal follow-up > 15 years showed that the incidence rates of postpartum diabetes remained relatively stable 10 to 20 years after the period of early conversion to diabetes $[26,34,46]$. The incidence of diabetes over time seems to increase with aging, which is another major risk factor for diabetes. Overall, the incidence of postpartum diabetes is higher during the early postpartum period and remains stable thereafter.

\section{Other factors}

Study designs and methods may affect the reported incidence of postpartum diabetes. For instance, the incidence of GDM and postpartum diabetes can vary when different diagnostic criteria are applied. Exclusion of pre-gestational diabetes is not always successful because the majority of studies recruit subjects upon pregnancy. The postpartum follow-up loss of women with GDM has been a barrier in many studies and also exists in clinical practice. Only $\sim 25 \%$ of women with previous GDM underwent glucose screening at 6 to 12 weeks of postpartum [47]. The main factors that contributed to loss of postpartum follow-up included time pressure, emotional stress in adjusting to a baby, and fear of being diagnosed with diabetes $[48,49]$. Women with autoantibodies, including the glutamic acid decarboxylase antibody, are expected to increase the risk of developing postpartum diabetes $[50,51]$.

\section{RISK FACTORS FOR POSTPARUM DIABETES}

\section{Genetic risk factors}

Gestational diabetes mellitus

Many genetic variants that were previously reported to be associated with type 2 diabetes have been shown to be associated with GDM. Cho et al. [52] found that 18 single-nucleotide polymorphisms associated with type 2 diabetes, including CDKAL1, CDKN2A/2B, HHEX, $I_{G F} B P_{2}, S L C_{3} O A 8$, and $T C_{7} L_{2}$, were associated with GDM in Korean women. Associations of MTNR 1 [53] and $\mathrm{KCNQ}_{1}$ [54] with GDM were also identified in Korean studies. Meta-analyses investigating the association between common type 2 diabetes genetic variants and GDM discovered up to nine genetic variants at or near TCF7L2, GCK, KCNJ11, KCNQ1, CDKAL1, IGF2BP2, $M T N_{1} B$, and IRS1 [55,56]. The genetic variants found in these meta-analyses were commonly associated with GDM in both East Asians and Caucasians, but the allele frequencies of each variant differed among study populations [55].

Following the era of the candidate gene approach, the first genome-wide association study evaluating the risk of GDM was conducted in Korea by Kwak et al. [57]. A two-stage analysis, which included a total of 1,399 women with GDM and 2,025 nondiabetic control subjects, was performed. Two loci (rs775480 in CDKAL1 and rs10830962 near MTNR1B) were found to be associated with GDM. In that study, eight of 34 type 2 diabetes-associated loci were also shown to be associated with GDM (IGF2BP2, CDKAL1, CDKN2A/2B, IDE/HHEX, KCNQ1, CENTD2, and MTNR1B). As the number of subjects was not sufficient to fully power a genome-wide association 
study, genetic variants specifically associated with GDM but not with type 2 diabetes may be identified in future studies.

The majority of genetic alterations associated with GDM, except IRS1, are functionally associated with $\beta$-cell insulin secretion but not insulin resistance. PPARG, which is associated with insulin resistance, was not associated with GDM [55,56]. Inherited genetic alterations affecting pancreatic $\beta$-cell function seem to play an important role in the development of GDM.

\section{Postpartum diabetes}

In contrast to genetic studies on GDM, not many stud-

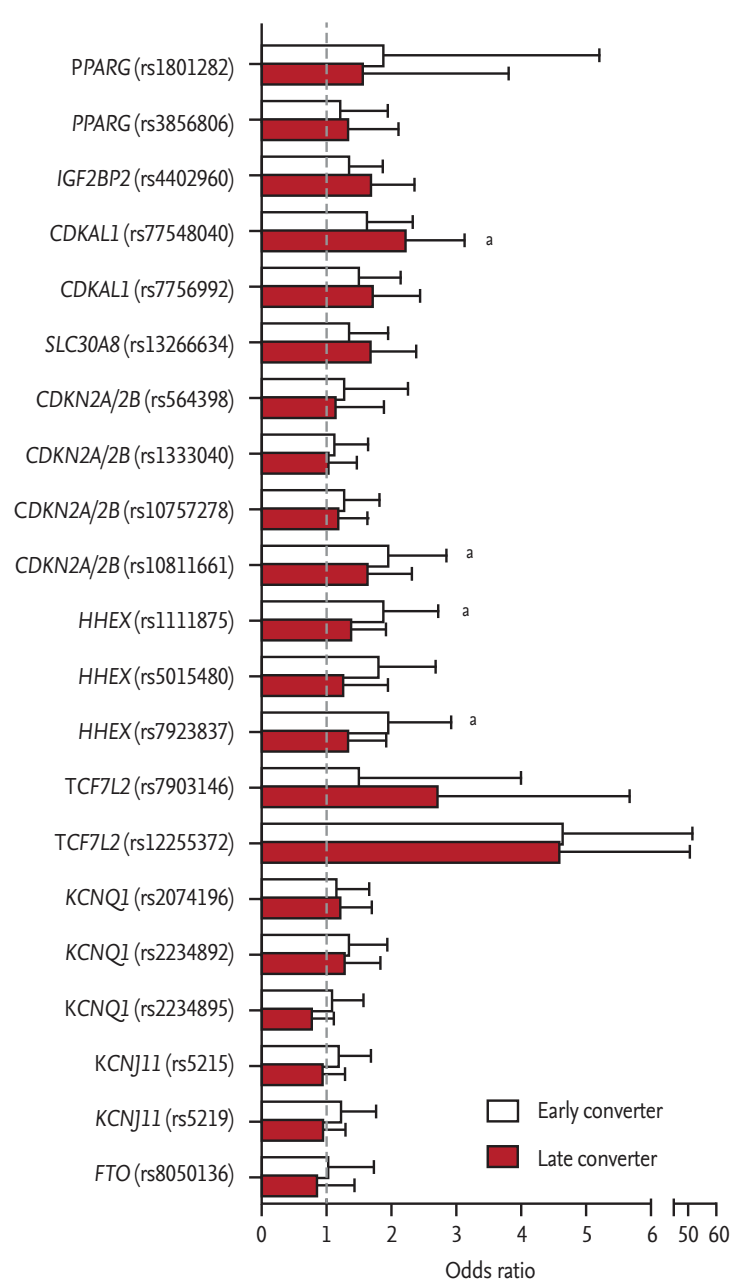

Figure 2. Genetic risk factors for early ( $\leq 8$ weeks) and late $\left(>1\right.$ year) conversion to postpartum diabetes. ${ }^{a} p$ value $<$ with the significance after Bonferroni correction $(0.05 / 10 / 2=$ $0.0025)$. ies have evaluated the genetic risk factors for postpartum diabetes. A total of 21 genetic variants associated with type 2 diabetes were genotyped among 634 Korean women with previous GDM, and genetic variants near $C D K N 2 A / 2 B$ and HHEX were associated with early conversion ( $\leq 8$ weeks postpartum) to postpartum diabetes, and those near CDKAL1 were associated with late conversion (> 1 year postpartum) (Fig. 2) [36]. Kwak et al. [58] generated a genetic risk score (GRS) that consists of 48 genetic variants associated with type 2 diabetes and validated that adding GRS to clinical models significantly increased the predictability of postpartum diabetes among 395 Korean women with previous GDM (net reclassification index $0.430, p=7.0 \times 10^{-5}$ ). To our knowledge, no genome-wide association study has been conducted to discover specific genetic variants related to postpartum diabetes in women with previous GDM.

GDM and postpartum diabetes are not separate diseases but rather exist on a continuum among women predisposed to insufficient $\beta$-cell capacity. Women with genetic variants for GDM and/or type 2 diabetes are expected to have a higher risk of postpartum diabetes, but further studies are needed to discover the specific genetic variants associated with postpartum diabetes.

\section{Environmental risk factors}

Various risk factors for postpartum diabetes in women with GDM have been identified, including maternal age [59], family history of diabetes [6o], extent of hyperglycemia during pregnancy [61], insulin treatment in pregnancy [50], and pre-pregnancy and postpartum BMI [30,62]. Among these, fasting plasma glucose level in pregnancy was consistently associated with postpartum diabetes in various major studies $[24,61,63-65]$. Other glycemic indices, including 1-hour [66] and 2-hour plasma glucose on OGTT [30,32], the area under the curve on OGTT [64], basal and stimulated insulin [32,36,67], and $\beta$-cell compensation in response to insulin resistance $[59,66]$, were associated with the development of postpartum diabetes. A number of studies conducted in Korea identified risk factors consistent with previous findings. Kwak et al. [36] demonstrated that pre-pregnancy BMI, a higher area under the curve on OGTT, low fasting insulin, and decreased $\beta$-cell secretion were independent risk factors for early conversion to postpartum diabetes. Jang et al. [30] found that pre-pregnancy weight, age, 2-hour 


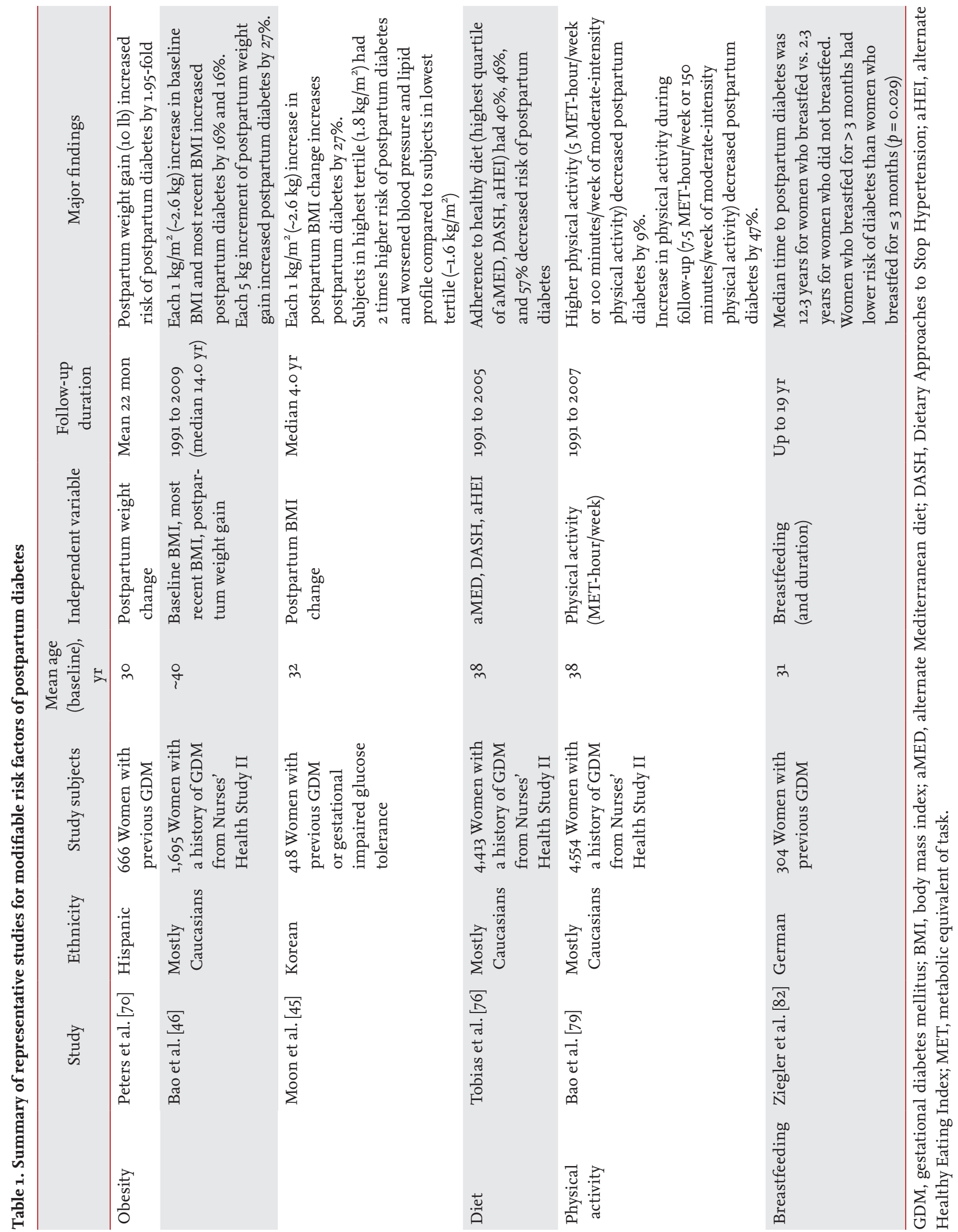


glucose, and 3-hour insulin levels were independently associated with postpartum diabetes. In a recent Korean study, women with postpartum diabetes were found to have higher HbAlc and all (1-, 2-, and 3-hour) glucose levels on 100-g OGTTs [68].

The risk factors mentioned above, including age, family history of diabetes, and glycemic indices during pregnancy, are factors that are not modifiable after delivery. In contrast, postpartum weight reduction, healthy diet, exercise, and breastfeeding are factors that can be ameliorated using lifestyle interventions for women with previous GDM (Table 1). Therefore, clinicians should focus on improving these modifiable risk factors to aid in the prevention of postpartum diabetes.

\section{Obesity}

Weight gain is a well-known risk factor for type 2 diabetes in the general population [69]. There are several studies from North America that reported the association between weight gain and increased risk of postpartum diabetes in women with previous GDM. Peters et al. [70] followed 666 Hispanic women with GDM and demonstrated that a $4.5 \mathrm{~kg}(10 \mathrm{lb})$ weight gain increased the risk of developing diabetes by 1.54-fold during a 2.2-year follow-up period (baseline BMI, $29.4 \mathrm{~kg} / \mathrm{m}^{2}$ ). Bao et al. [46] analyzed 1,695 women with GDM as a part of the Nurses' Health Study, and the incidence of diabetes increased by $27 \%$ for each $5 \mathrm{~kg}$ of weight gain (baseline BMI not given). Xiang et al. [71] demonstrated that weight gain was strongly associated with declining $\beta$-cell secretory capacity measured using the disposition index.

Although the effect of weight gain on postpartum diabetes is assumed to be similar, the baseline maternal BMI of Asians is usually lower than that of Caucasians. For this reason, a prospective cohort study was conducted in Korea by Moon et al. [45] which included 418 Korean women with GDM (baseline BMI $23.3 \mathrm{~kg} / \mathrm{m} 2$ ). This study demonstrated that subjects in the highest tertile of postpartum BMI change had $\sim 2$-fold higher risk of developing diabetes compared with women in the lowest tertile (mean BMI change in each tertile, 1.6 and - $1.8 \mathrm{~kg} /$ $\mathrm{m}^{2}$, respectively) [45]. In this study, postpartum weight gain did not merely affect development of diabetes but was also associated with other metabolic phenotypes, including lipid profile, blood pressure, and dynamic glycemic parameters (e.g., Matsuda and insulinogenic

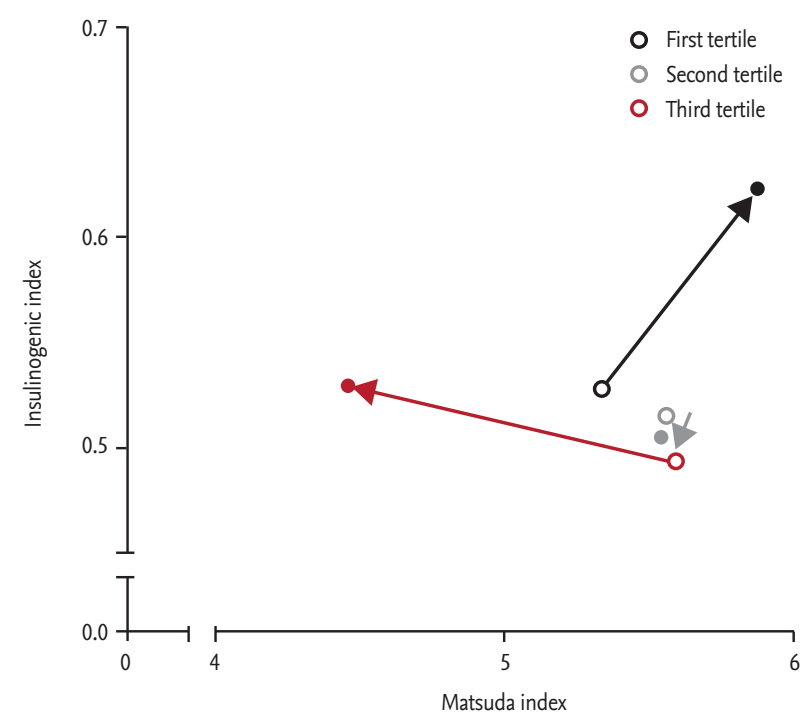

Figure 3. Changes in insulin sensitivity (Matsuda index) and insulin secretory function (insulinogenic index) according to postpartum body mass index (BMI) change during 4 years of follow-up. Changes in insulin sensitivity and secretory function by tertiles of postpartum BMI change were depicted (open circle, initial postpartum visit; closed circle, last follow-up). Subjects in the first tertile (who lost weight during follow-up) showed improvements in both insulin sensitivity and insulin secretion, whereas subjects in the third tertile (who gained weight during follow-up) had significant deterioration in insulin sensitivity but were not able to compensate by increasing their insulin secretion during follow-up. Adapted from Moon et al. [45], with permission from Endocrine Society.

indices) (Fig. 3).

Obesity parameters other than BMI or weight were also found to be associated with postpartum diabetes. Cho et al. [37] demonstrated that a series of obesity parameters, including waist circumference, skinfold thickness, and body fat weight were associated with postpartum diabetes, with waist circumference being the strongest predictor. Lim et al. [72] performed frequently sampled intravenous glucose tolerance tests in women with previous GDM with impaired glucose tolerance and demonstrated that high visceral fat content contributed to the development of impaired postpartum glucose tolerance. High homocysteine [73], high RBP-4 [74], and low adiponectin [74] were also associated with the severity of postpartum glucose intolerance. These findings highlight that increased adiposity or insulin resistance may accelerate the progression to postpartum 
diabetes when $\beta$-cells fail to compensate.

Diet

Dietary patterns are closely associated with the development of diabetes [75]. Women with GDM in the Nurses' Health Study who showed greater adherence to healthier diets as evidenced by a score in the highest quartile for the alternate Mediterranean diet, Dietary Approaches to Stop Hypertension diet, and alternate Healthy Eating Index diet had a $40 \%$ to $57 \%$ lower risk of developing postpartum diabetes compared with women in the lowest quartile [76]. In Korea, carbohydrates represent more than $70 \%$ of total energy intake [77]. It is not known whether the Korean diet has deleterious effects on glucose metabolism, but women with previous GDM should be careful not to consume too many calories and/or carbohydrates.

\section{Physical activity}

Physical activity is known to reduce the incidence of type 2 diabetes [78]. Women with GDM who had physical activity levels higher than a 7.5 metabolic equivalent of task-hours/week had a $47 \%$ lower risk of postpartum diabetes [79]. Several lifestyle interventional trials involving dietary changes and exercise encouragement among women with previous GDM were conducted to decrease the incidence of postpartum diabetes. These trials are further discussed in detail below.

\section{Breastfeeding}

Breastfeeding provides benefits to both the mother and her offspring. In a previous study, neonates who were breastfed were less likely to become overweight [80] and to develop type 2 diabetes in adulthood [81]. Ziegler et al. [82] followed German women with GDM for up to 19 years and found that breastfeeding $>3$ months reduced postpartum diabetes by $46 \%$. Amelioration of lipid profiles [83] and reduced postpartum weight retention [84] were also observed in studies involving women with GDM. In the Nurses' Health Study, each additional year of breastfeeding reduced the risk of diabetes by $15 \%$ even in mothers without GDM [85]. Breastfeeding was also associated with increased weight loss and decreased skinfold thickness [86]. These benefits are partly mediated by decreased circulating estrogen levels during lactation $[87,88]$. Breastfeeding should be strongly encouraged in women with a previous GDM diagnosis to promote both maternal and offspring health.

\section{INTERVENTIONAL MODALITIES IN WOMEN WITH GDM}

\section{Benefits of lifestyle interventions}

A number of studies have demonstrated that lifestyle interventions can prevent or delay the onset of diabetes in high-risk populations. The Diabetes Prevention Program (DPP) is a representative multicenter randomized interventional trial that aimed to demonstrate that either intensive lifestyle modifications or metformin could prevent the development of diabetes in high-risk men and women with impaired glucose tolerance [89]. The lifestyle intervention reduced the incidence of diabetes by $58 \%$ during a 2.8 -year follow-up period. This benefit was maintained during 10 years of follow-up, resulting in a $34 \%$ reduction in the incidence of diabetes in the lifestyle intervention group [90]. Systolic and diastolic blood pressure and triglyceride levels were also lower in subjects who underwent lifestyle modifications. Likewise, lifestyle interventional trials have been attempted among pregnant women.

\section{Prevention of GDM}

It is important to prevent high-risk pregnant women from developing GDM. Several lifestyle interventional trials have been conducted among obese pregnant women, but the effects of lifestyle modifications on gestational weight gain and GDM were inconsistent. Some trials succeeded in decreasing gestational weight gain [91-94], but others failed to decrease weight gain during pregnancy [95,96]. In a study from Denmark, although reduction in gestational weight gain was achieved, a significant number of women still exceeded the Institute of Medicine recommendations for gestational weight gain [94]. The Finnish Gestational Diabetes Prevention Study (RADIEL) is a representative study that succeeded in decreasing the incidence of GDM using a lifestyle intervention, which recruited 293 high-risk women with previous GDM or a pre-pregnancy BMI $\geq 30 \mathrm{~kg} / \mathrm{m}^{2}$ [97]. Individualized lifestyle interventions reduced GDM by $39 \%(13.9 \%$ for the intervention group and $21.6 \%$ for controls) and resulted in an additional weight loss of 


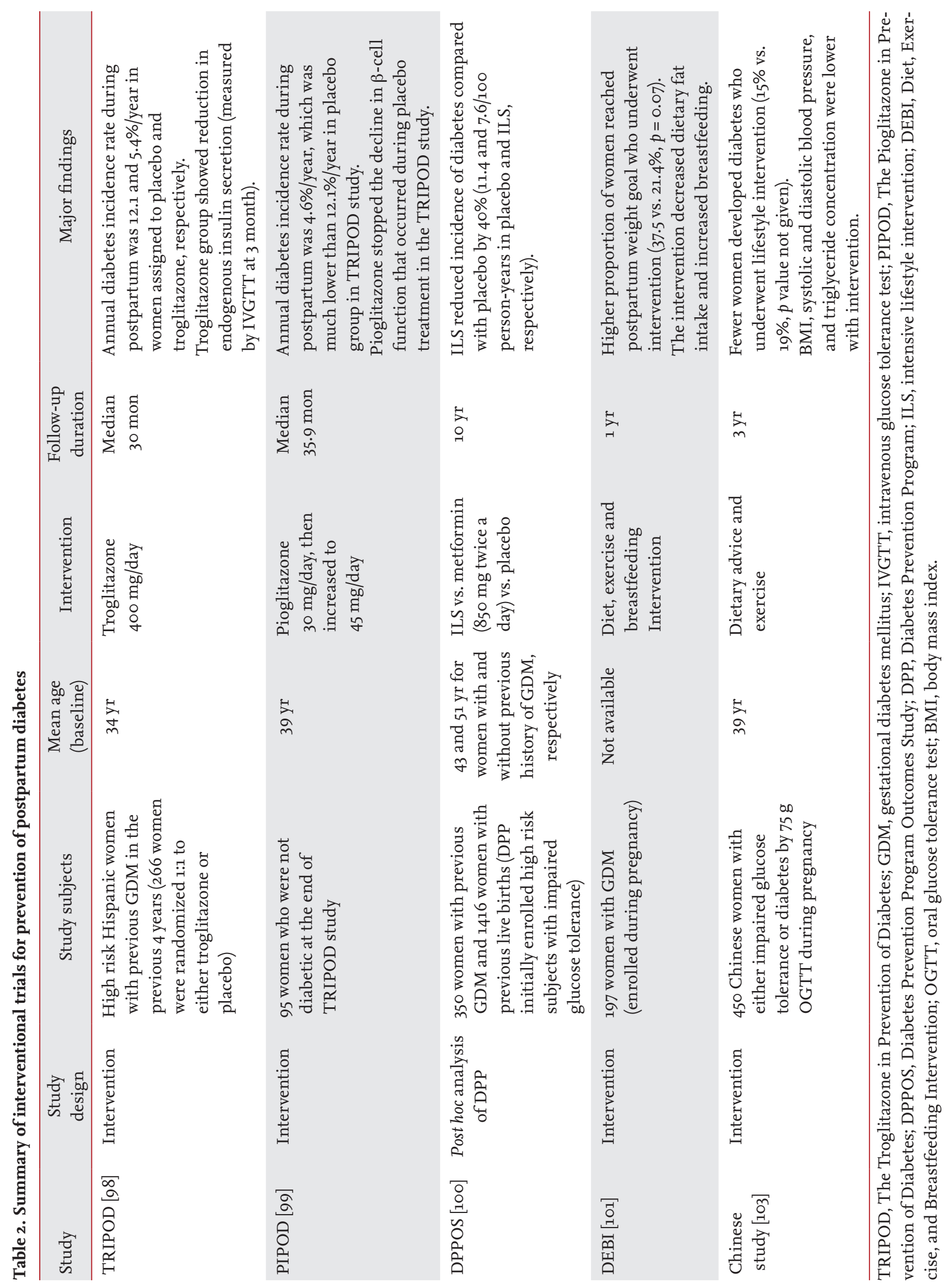


$0.58 \mathrm{~kg}$. Thus, lifestyle interventions seem beneficial for preventing GDM and reducing gestational weight gain; however, further studies are required to confirm the soundness of this association.

\section{Prevention of postpartum diabetes}

Interventional trials that aimed to prevent postpartum diabetes in women with previous GDM were conducted among non-Korean populations (Table 2). The Troglitazone in Prevention of Diabetes (TRIPOD) study recruited only young Hispanic women who were diagnosed with GDM within 4 years postpartum (mean age, 34 years) [98]. Subjects who were given troglitazone had a $55 \%$ reduction in the risk of diabetes progression $(12.1 \%$ per year for placebo, and 5.4\% per year for troglitazone). The authors hypothesized that reducing insulin resistance using thiazolidinedione preserved $\beta$-cell function by reducing insulin secretory demands. The Pioglitazone in Prevention of Diabetes (PIPOD) study was a subsequent study that included diabetes-free subjects who completed the TRIPOD study and were given pioglitazone; the incidence rate of diabetes was $4.6 \%$ per year, which was considerably lower than the diabetes rate for the placebo group in the TRIPOD study [99].

The 10-year observational cohort that followed the DPP study, the Diabetes Prevention Program Outcomes Study (DPPOS), demonstrated that intensive lifestyle modifications and metformin reduced the cumulative incidence of diabetes in women with a previous GDM diagnosis by $35 \%$ and $40 \%$, respectively, compared with the placebo group [100]. Participants (mean age, 43) had their last delivery a mean of 12 years before enrollment, as this trial did not primarily target women with previous GDM. Nevertheless, the results of this study suggest that interventions, such as lifestyle modifications and/ or metformin treatment, are effective for preventing the progression to diabetes, even years after delivery.

Ferrara et al. [101] performed a randomized controlled feasibility trial, the Diet, Exercise, and Breastfeeding Intervention (DEBI), among women with previous GDM. The intervention decreased dietary fat intake and increased breastfeeding with borderline significance, but physical activity levels did not differ. This resulted in a higher proportion of women reaching their postpartum weight goal (pre-pregnancy weight for women with pregravid $\mathrm{BMI}<25 \mathrm{~kg} / \mathrm{m}^{2}$ and an additional $5 \%$ loss from pre-pregnancy weight for women with pregravid BMI $\geq 25 \mathrm{~kg} / \mathrm{m}^{2}$ ), although this was statistically insignificant. In this trial, women who lost more than $2 \mathrm{~kg}$ exhibited reduced fasting and 2-hour glucose levels and increased 2-hour insulin levels at 12 months postpartum [102].

One interventional trial in Asia, which involved Chinese women with previous GDM who had impaired glucose tolerance on postpartum OGTT, offered advice on diet and exercise [103]. Fewer women who were provided the lifestyle intervention developed postpartum diabetes during a 3-year follow-up period compared with the control group, but this was without statistical significance ( $15 \%$ vs. $19 \%$, p value not given). A subgroup analysis showed that women aged $>40$ years had a significantly lower incidence of postpartum diabetes $(9.3 \%$ vs. $22.5 \%, p=0.018)$. BMI, systolic and diastolic blood pressure, and triglyceride concentrations were lower in the intervention group, but the significance of these results was inconsistent over time.

Several issues raised by the previous trials should be considered. First, weight reduction by lifestyle modification was modest in women with previous GDM compared with in non-GDM women. In the DPP study, the 3-year weight change in women with previous GDM was $-1.6 \mathrm{~kg}$, whereas it was $-4.0 \mathrm{~kg}$ in women without GDM [104]. The reasons underlying this difference are unknown but may be due to predisposition or poor compliance with lifestyle interventions among women with GDM. A more active and comprehensive strategy should be sought to achieve distinct metabolic benefits among those with GDM. Next, although the weight-loss effect of these interventions was inconsistent when considering study design, lifestyle modifications should still be encouraged to prevent various obesity-related morbidities, including postpartum diabetes and dyslipidemia. Lifestyle interventions have shown better or equivalent effects on reducing postpartum diabetes when compared with antidiabetic medications [89,104]. Lastly, as Asian women have relatively lower BMIs than nonAsians, the effects of interventions may differ across populations. Indeed, further studies are warranted to clarify the metabolic benefits of lifestyle interventions in Asian populations. 


\section{CONCLUSIONS}

Women with previous GDM have more than a 7 -fold higher risk of developing postpartum diabetes compared with women without GDM. Various risk factors for postpartum diabetes, including age, glucose level in pregnancy, family history of diabetes, obesity, physical activity, and breastfeeding, were identified in previous studies. Recent interventional trials have shown that lifestyle modifications and/or antidiabetic medications have metabolic benefits, such as reducing postpartum diabetes, but these interventions were not as effective as they were in the non-gravid population. Nonetheless, lifestyle modifications are strongly recommended for women with previous GDM [105,106].

In clinical practice, the loss of women with GDM to follow-up evaluations after delivery is problematic. The majority of women with GDM understand the association between GDM and postpartum diabetes but do not perceive themselves at increased risk of developing diabetes [107]. Postpartum diabetes screening rates range from $19 \%$ to $73 \%$, which are generally poor compared with expectations [48]. Automated reminders or notifications sent to women diagnosed with GDM would help to detect postpartum diabetes and guide women regarding subsequent follow-up [108,109].

Asians have a different genetic predisposition to diabetes and have relatively low BMIs compared with other ethnicities. However, many previous studies covered in this review were conducted in Western countries. Although the risk factors for postpartum diabetes and the metabolic benefits of lifestyle modifications are assumed to be similar, further studies investigating the prevention of postpartum diabetes in Asian populations are warranted.

\section{Conflict of interest}

No potential conflict of interest relevant to this article was reported.

\section{Acknowledgments}

This research was supported by grants from Seoul National University Bundang Hospital (02-2012-009) and the Korea Healthcare Technology R \& D Project, Ministry of Health and Welfare (Grant no. A111362).

\section{REFERENCES}

1. Metzger BE, Coustan DR. Summary and recommendations of the Fourth International Workshop-Conference on Gestational Diabetes Mellitus: the Organizing Committee. Diabetes Care 1998;21 Suppl 2:B161-B167.

2. Ferrara A. Increasing prevalence of gestational diabetes mellitus: a public health perspective. Diabetes Care 2007;30 Suppl 2:S141-S146.

3. Korean Diabetes Association. Diabetes Fact Sheet in Korea 2013 [Internet]. Seoul (KR): Korean Diabetes Association, c2011 [cited 2016 Dec 5]. Available from: http://www. diabetes.or.kr/temp/diabetes_factsheet_2013111.pdf.

4. Cho GJ, Kim LY, Sung YN, et al. Secular trends of gestational diabetes mellitus and changes in its risk factors. PLoS One 2015;10:e0136017.

5. Kim C. Gestational diabetes mellitus in Korean women: similarities and differences from other racial/ethnic groups. Diabetes Metab J 2014;38:1-12.

6. Xiang AH, Takayanagi M, Black $\mathrm{MH}$, et al. Longitudinal changes in insulin sensitivity and beta cell function between women with and without a history of gestational diabetes mellitus. Diabetologia 2013;56:2753-276o.

7. Kim C, Newton KM, Knopp RH. Gestational diabetes and the incidence of type 2 diabetes: a systematic review. Diabetes Care 2002;25:1862-1868.

8. Jang HC. Gestational diabetes in Korea: incidence and risk factors of diabetes in women with previous gestational diabetes. Diabetes Metab J 2011;35:1-7.

9. Heitritter SM, Solomon CG, Mitchell GF, Skali-Ounis N, Seely EW. Subclinical inflammation and vascular dysfunction in women with previous gestational diabetes mellitus. J Clin Endocrinol Metab 2005;90:3983-3988.

10. Edwards M, Meltzer S, Rahme E, Dasgupta K. Predictors of postpartum lipid abnormalities in women with gestational diabetes. Can J Diabetes 2012;36:305-309.

11. Carpenter MW, Coustan DR. Criteria for screening tests for gestational diabetes. Am J Obstet Gynecol 1982;144:768-773.

12. O'Sullivan JB, Mahan CM. Criteria for the oral glucose tolerance test in pregnancy. Diabetes 1964;13:278-285.

13. O'Sullivan JB. The Boston gestational diabetes studies: review and perspectives. In: Sutherland HW, Stowers JM, Pearson WM, eds. Carbohydrate Metabolism in Pregnancy and the Newborn IV. London: Springer, 1989:287-294.

14. Berggren EK, Boggess KA, Stuebe AM, Jonsson Funk M. 
National Diabetes Data Group vs Carpenter-Coustan criteria to diagnose gestational diabetes. Am J Obstet Gynecol 2011;205:253.e1-253.e7.

15. Jang HC, Cho YM, Park KS, et al. Pregnancy outcome in Korean women with gestational diabetes mellitus diagnosed by the Carpenter-Coustan criteria. J Korean Diabetes Assoc 2004;28:122-130.

16. Metzger BE, Buchanan TA, Coustan DR, et al. Summary and recommendations of the Fifth International Workshop-Conference on Gestational Diabetes Mellitus. Diabetes Care 2007;30 Suppl 2:S251-S260.

17. International Association of Diabetes and Pregnancy Study Groups Consensus Panel, Metzger BE, Gabbe SG, et al. International association of diabetes and pregnancy study groups recommendations on the diagnosis and classification of hyperglycemia in pregnancy. Diabetes Care 2010;33:676-682.

18. HAPO Study Cooperative Research Group, Metzger BE, Lowe LP, et al. Hyperglycemia and adverse pregnancy outcomes. N Engl J Med 2008;358:1991-2002.

19. Balion CM, Raina PS, Gerstein HC, et al. Reproducibility of impaired glucose tolerance (IGT) and impaired fasting glucose (IFG) classification: a systematic review. Clin Chem Lab Med 2007;45:1180-1185.

20. American Diabetes Association. 2. Classification and diagnosis of diabetes. Diabetes Care 2016;39 Suppl 1:S13-S22.

21. Korean Diabetes Association. Treatment guideline for diabetes 2015 [Internet]. Seoul (KR): Korean Diabetes Association, c2011 [cited 2016 Dec 6]. Available from: http:// www.diabetes.or.kr/pro/publish/guide.php?code=guide\&mode $=$ view $\&$ number $=625$.

22. Committee on Practice Bulletins-Obstetrics. Practice Bulletin no. 137: Gestational diabetes mellitus. Obstet Gynecol 2013;122(2 Pt 1):406-416.

23. Persson B, Hanson U, Hartling SG, Binder C. Follow-up of women with previous GDM. Insulin, C-peptide, and proinsulin responses to oral glucose load. Diabetes 1991;40 Suppl 2:136-141.

24. Damm P, Kuhl C, Buschard K, et al. Prevalence and predictive value of islet cell antibodies and insulin autoantibodies in women with gestational diabetes. Diabet Med 1994;11:558-563.

25. Diabetes mellitus: report of a WHO Study Group. World Health Organ Tech Rep Ser 1985;727:1-113.

26. Gunderson EP, Lewis CE, Tsai AL, et al. A 20-year prospective study of childbearing and incidence of diabetes in young women, controlling for glycemia before conception: the Coronary Artery Risk Development in Young Adults (CARDIA) Study. Diabetes 2007:56:2990-2996.

27. Vambergue A, Dognin C, Boulogne A, Rejou MC, Biausque $S$, Fontaine P. Increasing incidence of abnormal glucose tolerance in women with prior abnormal glucose tolerance during pregnancy: DIAGEST 2 study. Diabet Med 2008;25:58-64.

28. Morimitsu LK, Fusaro AS, Sanchez VH, Hagemann CC, Bertini AM, Dib SA. Fibrinolytic dysfunction after gestation is associated to components of insulin resistance and early type 2 diabetes in latino women with previous gestational diabetes. Diabetes Res Clin Pract 2007;78:340348.

29. World Health Organization. Definition, diagnosis and classification of diabetes mellitus and its complications. Report of a WHO consultation, part 1: diagnosis and classification of diabetes mellitus. Geneva: World Health Organization, 1999.

30. Jang HC, Yim CH, Han KO, et al. Gestational diabetes mellitus in Korea: prevalence and prediction of glucose intolerance at early postpartum. Diabetes Res Clin Pract 2003;61:117-124.

31. Geiss LS, Wang J, Cheng YJ, et al. Prevalence and incidence trends for diagnosed diabetes among adults aged 20 to 79 years, United States, 1980-2012. JAMA 2014;312:1218-1226.

32. Metzger BE, Cho NH, Roston SM, Radvany R. Prepregnancy weight and antepartum insulin secretion predict glucose tolerance five years after gestational diabetes mellitus. Diabetes Care 1993;16:1598-1605.

33. Retnakaran R, Qi Y, Sermer M, Connelly PW, Hanley AJ, Zinman B. Glucose intolerance in pregnancy and future risk of pre-diabetes or diabetes. Diabetes Care 2008;31:2026-2031.

34. Linne Y, Barkeling B, Rossner S. Natural course of gestational diabetes mellitus: long term follow up of women in the SPAWN study. BJOG 2002;109:1227-1231.

35. Bellamy L, Casas JP, Hingorani AD, Williams D. Type 2 diabetes mellitus after gestational diabetes: a systematic review and meta-analysis. Lancet 2009;373:1773-1779.

36. Kwak SH, Choi SH, Jung HS, et al. Clinical and genetic risk factors for type 2 diabetes at early or late post partum after gestational diabetes mellitus. J Clin Endocrinol Metab 2013;98:E744-E752.

37. Cho NH, Jang HC, Park HK, Cho YW. Waist circumfer- 
ence is the key risk factor for diabetes in Korean women with history of gestational diabetes. Diabetes Res Clin Pract 2006;71:177-183.

38. Lee H, Jang HC, Park HK, Metzger BE, Cho NH. Prevalence of type 2 diabetes among women with a previous history of gestational diabetes mellitus. Diabetes Res Clin Pract 2008;81:124-129.

39. Yang SJ, Kim TN, Baik SH, et al. Insulin secretion and insulin resistance in Korean women with gestational diabetes mellitus and impaired glucose tolerance. Korean J Intern Med 2013;28:306-313.

40. Ohn JH, Kwak SH, Cho YM, et al. 10-year trajectory of beta-cell function and insulin sensitivity in the development of type 2 diabetes: a community-based prospective cohort study. Lancet Diabetes Endocrinol 2016;4:27-34.

41. Kong AP, Xu G, Brown N, So WY, Ma RC, Chan JC. Diabetes and its comorbidities: where East meets West. Nat Rev Endocrinol 2013;9:537-547.

42. Hedderson M, Ehrlich S, Sridhar S, Darbinian J, Moore S, Ferrara A. Racial/ethnic disparities in the prevalence of gestational diabetes mellitus by BMI. Diabetes Care 2012;35:1492-1498.

43. Kousta E, Efstathiadou Z, Lawrence NJ, et al. The impact of ethnicity on glucose regulation and the metabolic syndrome following gestational diabetes. Diabetologia 2006;49:36-40.

44. Ignell C, Shaat N, Ekelund M, Berntorp K. The impact of ethnicity on glucose homeostasis after gestational diabetes mellitus. Acta Diabetol 2013;50:927-934.

45. Moon JH, Kwak SH, Jung HS, et al. Weight gain and progression to type 2 diabetes in women with a history of gestational diabetes mellitus. J Clin Endocrinol Metab 2015;100:3548-3555.

46. Bao W, Yeung E, Tobias DK, et al. Long-term risk of type 2 diabetes mellitus in relation to BMI and weight change among women with a history of gestational diabetes mellitus: a prospective cohort study. Diabetologia 2015;58:1212-1219.

47. Kim C, Tabaei BP, Burke R, et al. Missed opportunities for type 2 diabetes mellitus screening among women with a history of gestational diabetes mellitus. Am J Public Health 2006;96:1643-1648.

48. Nielsen KK, Kapur A, Damm P, de Courten M, Bygbjerg IC. From screening to postpartum follow-up: the determinants and barriers for gestational diabetes mellitus (GDM) services, a systematic review. BMC Pregnancy
Childbirth 2014;14:41.

49. Bennett WL, Ennen CS, Carrese JA, et al. Barriers to and facilitators of postpartum follow-up care in women with recent gestational diabetes mellitus: a qualitative study. J Womens Health (Larchmt) 2011;20:239-245.

50. Lobner K, Knopff A, Baumgarten A, et al. Predictors of postpartum diabetes in women with gestational diabetes mellitus. Diabetes 2006;55:792-797.

51. Yu SH, Park S, Kim HS, et al. The prevalence of GAD antibodies in Korean women with gestational diabetes mellitus and their clinical characteristics during and after pregnancy. Diabetes Metab Res Rev 2009;25:329-334.

52. Cho YM, Kim TH, Lim S, et al. Type 2 diabetes-associated genetic variants discovered in the recent genome-wide association studies are related to gestational diabetes mellitus in the Korean population. Diabetologia 2009;52:253261.

53. Kim JY, Cheong HS, Park BL, et al. Melatonin receptor 1 B polymorphisms associated with the risk of gestational diabetes mellitus. BMC Med Genet 2011;12:82.

54. Shin HD, Park BL, Shin HJ, et al. Association of KCNQ1 polymorphisms with the gestational diabetes mellitus in Korean women. J Clin Endocrinol Metab 2010;95:445-449.

55. Mao H, Li Q, Gao S. Meta-analysis of the relationship between common type 2 diabetes risk gene variants with gestational diabetes mellitus. PLoS One 2012;7:e45882.

56. Zhang C, Bao W, Rong Y, et al. Genetic variants and the risk of gestational diabetes mellitus: a systematic review. Hum Reprod Update 2013;19:376-390.

57. Kwak SH, Kim SH, Cho YM, et al. A genome-wide association study of gestational diabetes mellitus in Korean women. Diabetes 2012;61:531-541.

58. Kwak SH, Choi SH, Kim K, et al. Prediction of type 2 diabetes in women with a history of gestational diabetes using a genetic risk score. Diabetologia 2013;56:2556-2563.

59. Grant PT, Oats JN, Beischer NA. The long-term follow-up of women with gestational diabetes. Aust N Z J Obstet Gynaecol 1986;26:17-22.

6o. Henry OA, Beischer NA. Long-term implications of gestational diabetes for the mother. Baillieres Clin Obstet Gynaecol 1991;5:461-483.

61. Coustan DR, Carpenter MW, O'Sullivan PS, Carr SR. Gestational diabetes: predictors of subsequent disordered glucose metabolism. Am J Obstet Gynecol 1993;168:11391144 .

62. Catalano PM, Vargo KM, Bernstein IM, Amini SB. Inci- 
dence and risk factors associated with abnormal postpartum glucose tolerance in women with gestational diabetes. Am J Obstet Gynecol 1991;165(4 Pt 1):914-919.

63. Kjos SL, Buchanan TA, Greenspoon JS, Montoro M, Bernstein GS, Mestman JH. Gestational diabetes mellitus: the prevalence of glucose intolerance and diabetes mellitus in the first two months post partum. Am J Obstet Gynecol 1990;163(1 Pt 1):93-98.

64. Kjos SL, Peters RK, Xiang A, Henry OA, Montoro M, Buchanan TA. Predicting future diabetes in Latino women with gestational diabetes: utility of early postpartum glucose tolerance testing. Diabetes 1995;44:586-591.

65. Lam KS, Li DF, Lauder IJ, Lee CP, Kung AW, Ma JT. Prediction of persistent carbohydrate intolerance in patients with gestational diabetes. Diabetes Res Clin Pract 1991;12:181-186.

66. Buchanan TA, Xiang AH, Kjos SL, Trigo E, Lee WP, Peters RK. Antepartum predictors of the development of type 2 diabetes in Latino women 11-26 months after pregnancies complicated by gestational diabetes. Diabetes 1999;48:2430-2436.

67. Damm P, Kuhl C, Bertelsen A, Molsted-Pedersen L. Predictive factors for the development of diabetes in women with previous gestational diabetes mellitus. Am J Obstet Gynecol 1992;167:607-616.

68. Shin NR, Yoon SY, Cho GJ, et al. A Korean multicenter study of prenatal risk factors for overt diabetes during the postpartum period after gestational diabetes mellitus. Int J Gynaecol Obstet 2016;132:342-346.

69. Colditz GA, Willett WC, Rotnitzky A, Manson JE. Weight gain as a risk factor for clinical diabetes mellitus in women. Ann Intern Med 1995;122:481-486.

70. Peters RK, Kjos SL, Xiang A, Buchanan TA. Long-term diabetogenic effect of single pregnancy in women with previous gestational diabetes mellitus. Lancet 1996;347:227230.

71. Xiang AH, Kawakubo M, Trigo E, Kjos SL, Buchanan TA. Declining beta-cell compensation for insulin resistance in Hispanic women with recent gestational diabetes mellitus: association with changes in weight, adiponectin, and C-reactive protein. Diabetes Care 2010;33:396-401.

72. Lim S, Choi SH, Park YJ, et al. Visceral fatness and insulin sensitivity in women with a previous history of gestational diabetes mellitus. Diabetes Care 2007;30:348-353.

73. Cho NH, Lim S, Jang HC, Park HK, Metzger BE. Elevated homocysteine as a risk factor for the development of dia- betes in women with a previous history of gestational diabetes mellitus: a 4-year prospective study. Diabetes Care 2005;28:2750-2755.

74. Choi SH, Kwak SH, Youn BS, et al. High plasma retinol binding protein-4 and low plasma adiponectin concentrations are associated with severity of glucose intolerance in women with previous gestational diabetes mellitus. J Clin Endocrinol Metab 2008;93:3142-3148.

75. Kastorini CM, Panagiotakos DB. Dietary patterns and prevention of type 2 diabetes: from research to clinical practice: a systematic review. Curr Diabetes Rev 2009;5:221-227.

76. Tobias DK, Hu FB, Chavarro J, Rosner B, Mozaffarian D, Zhang C. Healthful dietary patterns and type 2 diabetes mellitus risk among women with a history of gestational diabetes mellitus. Arch Intern Med 2012;172:1566-1572.

77. Park SH, Lee KS, Park HY. Dietary carbohydrate intake is associated with cardiovascular disease risk in Korean: analysis of the third Korea National Health and Nutrition Examination Survey (KNHANES III). Int J Cardiol 2010;139:234-240.

78. Manson JE, Rimm EB, Stampfer MJ, et al. Physical activity and incidence of non-insulin-dependent diabetes mellitus in women. Lancet 1991;338:774-778.

79. Bao W, Tobias DK, Bowers K, et al. Physical activity and sedentary behaviors associated with risk of progression from gestational diabetes mellitus to type 2 diabetes mellitus: a prospective cohort study. JAMA Intern Med 2014;174:1047-1055.

8o. Grummer-Strawn LM, Mei Z; Centers for Disease Control and Prevention Pediatric Nutrition Surveillance System. Does breastfeeding protect against pediatric overweight? Analysis of longitudinal data from the Centers for Disease Control and Prevention Pediatric Nutrition Surveillance System. Pediatrics 2004;113:e81-e86.

81. Pettitt DJ, Forman MR, Hanson RL, Knowler WC, Bennett $\mathrm{PH}$. Breastfeeding and incidence of non-insulin-dependent diabetes mellitus in Pima Indians. Lancet 1997;350:166-168.

82. Ziegler AG, Wallner M, Kaiser I, et al. Long-term protective effect of lactation on the development of type 2 diabetes in women with recent gestational diabetes mellitus. Diabetes 2012;61:3167-3171.

83. Kjos SL, Henry O, Lee RM, Buchanan TA, Mishell DR Jr. The effect of lactation on glucose and lipid metabolism in women with recent gestational diabetes. Obstet Gyne- 
col 1993;82:451-455.

84. Olson CM, Strawderman MS, Hinton PS, Pearson TA. Gestational weight gain and postpartum behaviors associated with weight change from early pregnancy to $1 \mathrm{y}$ postpartum. Int J Obes Relat Metab Disord 2003;27:117127.

85. Stuebe AM, Rich-Edwards JW, Willett WC, Manson JE, Michels KB. Duration of lactation and incidence of type 2 diabetes. JAMA 2005;294:2601-2610.

86. Dewey KG, Heinig MJ, Nommsen LA. Maternal weightloss patterns during prolonged lactation. Am J Clin Nutr 1993:58:162-166.

87. Taylor JS, Kacmar JE, Nothnagle M, Lawrence RA. A systematic review of the literature associating breastfeeding with type 2 diabetes and gestational diabetes. J Am Coll Nutr 2005;24:320-326.

88. Lenz S, Kuhl C, Hornnes PJ, Hagen C. Influence of lactation on oral glucose tolerance in the puerperium. Acta Endocrinol (Copenh) 1981;98:428-431.

89. Knowler WC, Barrett-Connor E, Fowler SE, et al. Reduction in the incidence of type 2 diabetes with lifestyle intervention or metformin. N Engl J Med 2002;346:393-403.

90. Diabetes Prevention Program Research Group, Knowler WC, Fowler SE, et al. 10-Year follow-up of diabetes incidence and weight loss in the Diabetes Prevention Program Outcomes Study. Lancet 2009;374:1677-1686.

91. Quinlivan JA, Lam LT, Fisher J. A randomised trial of a four-step multidisciplinary approach to the antenatal care of obese pregnant women. Aust N Z J Obstet Gynaecol 2011;51:141-146.

92. Bogaerts AF, Devlieger R, Nuyts E, Witters I, Gyselaers W, Van den Bergh BR. Effects of lifestyle intervention in obese pregnant women on gestational weight gain and mental health: a randomized controlled trial. Int J Obes (Lond) 2013;37:814-821.

93. Walsh JM, McGowan CA, Mahony R, Foley ME, McAuliffe FM. Low glycaemic index diet in pregnancy to prevent macrosomia (ROLO study): randomised control trial. BMJ 2012;345:e5605.

94. Vinter CA, Jensen DM, Ovesen P, Beck-Nielsen H, Jorgensen JS. The LiP (Lifestyle in Pregnancy) study: a randomized controlled trial of lifestyle intervention in 360 obese pregnant women. Diabetes Care 2011;34:2502-2507.

95. Guelinckx I, Devlieger R, Mullie P, Vansant G. Effect of lifestyle intervention on dietary habits, physical activity, and gestational weight gain in obese pregnant women: a randomized controlled trial. Am J Clin Nutr 2010;91:373380.

96. Luoto R, Kinnunen TI, Aittasalo M, et al. Primary prevention of gestational diabetes mellitus and large-for-gestational-age newborns by lifestyle counseling: a cluster-randomized controlled trial. PLoS Med 2011;8:e1001036.

97. Koivusalo SB, Rono K, Klemetti MM, et al. Gestational diabetes mellitus can be prevented by lifestyle intervention: The Finnish Gestational Diabetes Prevention Study (RADIEL): A Randomized Controlled Trial. Diabetes Care 2016;39:24-30.

98. Buchanan TA, Xiang AH, Peters RK, et al. Preservation of pancreatic beta-cell function and prevention of type 2 diabetes by pharmacological treatment of insulin resistance in high-risk hispanic women. Diabetes 2002;51:2796-2803.

99. Xiang AH, Peters RK, Kjos SL, et al. Effect of pioglitazone on pancreatic beta-cell function and diabetes risk in Hispanic women with prior gestational diabetes. Diabetes 2006;55:517-522.

100. Aroda VR, Christophi CA, Edelstein SL, et al. The effect of lifestyle intervention and metformin on preventing or delaying diabetes among women with and without gestational diabetes: the Diabetes Prevention Program outcomes study 10-year follow-up. J Clin Endocrinol Metab 2015;100:1646-1653.

101. Ferrara A, Hedderson MM, Albright CL, et al. A pregnancy and postpartum lifestyle intervention in women with gestational diabetes mellitus reduces diabetes risk factors: a feasibility randomized control trial. Diabetes Care 2011;34:1519-1525.

102. Ehrlich SF, Hedderson MM, Quesenberry CP Jr, et al. Post-partum weight loss and glucose metabolism in women with gestational diabetes: the DEBI Study. Diabet Med 2014;31:862-867.

103. Shek NW, Ngai CS, Lee CP, Chan JY, Lao TT. Lifestyle modifications in the development of diabetes mellitus and metabolic syndrome in Chinese women who had gestational diabetes mellitus: a randomized interventional trial. Arch Gynecol Obstet 2014;289:319-327.

104. Ratner RE, Christophi CA, Metzger BE, et al. Prevention of diabetes in women with a history of gestational diabetes: effects of metformin and lifestyle interventions. J Clin Endocrinol Metab 2008;93:4774-4779.

105. Buchanan TA, Page KA. Approach to the patient with gestational diabetes after delivery. J Clin Endocrinol Metab 2011;96:3592-3598. 
106. Xiang AH, Peters RK, Kjos SL, et al. Pharmacological treatment of insulin resistance at two different stages in the evolution of type 2 diabetes: impact on glucose tolerance and beta-cell function. J Clin Endocrinol Metab 2004;89:2846-2851.

107. Kim C, McEwen LN, Piette JD, Goewey J, Ferrara A, Walker EA. Risk perception for diabetes among women with histories of gestational diabetes mellitus. Diabetes Care 2007;30:2281-2286.
108. Kim C, McEwen LN, Kerr EA, et al. Preventive counseling among women with histories of gestational diabetes mellitus. Diabetes Care 2007;30:2489-2495.

109. Clark HD, Graham ID, Karovitch A, Keely EJ. Do postal reminders increase postpartum screening of diabetes mellitus in women with gestational diabetes mellitus? A randomized controlled trial. Am J Obstet Gynecol 2009;200:634.e1-634.e7. 